\title{
Telepsychiatry as a mental health intervention for garment workers in Bangladesh: A 'Need of Hour' during COVID-19?
}

\author{
Tanjir R. Soron ${ }^{1}$, Tasdik M. Hasan², Yasmin Jahan³, Vivek Podder, Omar M. Salman ${ }^{5}$, Abu Sayeed ${ }^{6}$
}

\section{AFFILIATION}

1 Telepsychiatry Research and Innovation Network, Dhaka, Bangladesh 2 Department of Primary Care and Mental Health, University of Liverpool, Liverpool, United Kingdom

3 Graduate School of Biomedical and Health Sciences, Hiroshima University, Hiroshima, Japan

4 Tairunnessa Memorial Medical College and Hospital, Dhaka, Bangladesh 5 London School of Hygiene and Tropical Medicine, London, United Kingdom

6 Department of Post-Harvest Technology and Marketing, Patuakhali Science and Technology University, Patuakhali, Bangladesh

Popul. Med. 2020;2(October):32

\section{CORRESPONDENCE TO}

Abu Sayeed. Department of Post-Harvest Technology and Marketing, Patuakhali Science and Technology University, Patuakhali, 8602, Bangladesh.

E-mail: shuvo.nfs.pstu@gmail.com ORCID ID: https://orcid.org/00000003-0745-1755

\section{KEYWORDS}

telepsychiatry, garment worker, Bangladesh

Received: 20 July 2020, Accepted: 31 July 2020

https://doi.org/10.18332/popmed/125914

\section{Dear Editor,}

The global effects on the world economy of the COVID-19 pandemic has caused clothing brands and retailers to reduce their orders. This has put millions of garment workers in Bangladesh at risk of losing their job. Bangladesh Garments Manufacturers and Exporters Association (BGMEA) reported recent order cancellations worth of 3.18 billion US\$ from 1150 garment factories, resulting in 2.28 million workers remaining unpaid and 1 million losing their jobs ${ }^{1}$. These workers, primarily women and often the only breadwinner of their family, will subsequently suffer from acute poverty and food insecurity, resulting in an increased number of human rights abuses such as domestic violence. A past UK-funded study found $60 \%$ of female workers faced physical and/or verbal abuse ${ }^{2}$. Poor workplace conditions, low wages and few benefits within the employment facilities predispose garment workers to serious mental illness. In addition to global lockdowns and unprecedented job losses, garment workers' fear of contracting COVID-19, amidst this humanitarian crisis, will likely cause greater emotional and mental turmoil. The same UK-funded study also reported that $40 \%$ of female garment workers suffer from depressive symptomatology, and their analysis revealed intimate-partner violence, workrelated stress, poor general health, low self-esteem and low life satisfaction, likely contributing to their symptoms ${ }^{2}$. The degree of vulnerability to mental health problems indicates the need for increased mental health care for this vulnerable group of workers.

During the era of promoting 'no health without mental health', more than $90 \%$ of people in low- and middleincome countries are deprived of standard mental health care facilities ${ }^{3}$. Bangladesh is no way different and is struggling with poor public mental health services with a scarcity of skilled mental health professionals, limited resources, an overspread stigma on mental health, and weakened governance ${ }^{4}$. Despite the country's economic growth, working conditions for garment workers can hardly be described as adequate. Their unhealthy working environment, severe workload, low wages, poor living conditions, few recreational activities, repeated exposure to abuse, and widespread discrimination, are making them vulnerable to developing a wide array of mental disorders, with consequent absenteeism, lower productivity and poor concentration ${ }^{5}$. A recent report documented presence of widespread depression, personality disorder and somatization among the workers in the readymade garment industry in Bangladesh ${ }^{6}$. Interviewed stakeholders reported an urgent need for immediate evidence-based, cost-effective and gender-sensitive mental health care ${ }^{6}$.

The rapidly escalating COVID-19 pandemic has brought telemedicine into the light in many countries, including Bangladesh, with potential to revamp current approaches to patient care ${ }^{7}$. The Center for Disease Control (CDC) has encouraged using telemedicine platforms to provide remote and timely access to care and reduce transmission risks ${ }^{8}$. Telepsychiatry is popularly known as the medium of delivery of health care and the exchange of health information for the purpose of providing psychiatric services remotely, across widespread geographical areas ${ }^{9}$. This is particularly the 'need of hour' due to the fact that long waiting times, social stigmas and restricted access during pandemic situations, like COVID-19, make it difficult to receive mental health care. 
Studies have emphasized on the need for telepsychiatry in place during this crisis period ${ }^{7}$. A recent study emphasized adopting digital psychiatry services, such telepsychiatry for the mental health services due to the pandemic ${ }^{10}$. In recent times, telepsychiatry interventions have shown promise for the improvement of healthcare in many countries including low-resource settings. In Bangladesh, adequate internet and cellular coverage is available in almost every part of the country ${ }^{9}$, hence this approach could potentially serve basic mental health support to such an important group of workers. Also, mobile phone-based psychotherapies can be a convenient, feasible treatment option; and reminders inside such complex working settings save time, give flexible appointment schedules, ensure privacy and help to overcome the barrier of stigma. Furthermore, in Bangladesh, little has been done so far to implement telepsychiatry as a tool for mental health disorders ${ }^{5}$. This intervention for garment workers can potentially be one of the first few attempts to implement an innovative model to support occupational mental health and contribute to sustaining economic growth, by ensuring the wellbeing of the workers through an inclusive mental health system in Bangladesh and similar low-resource settings.

\section{REFERENCES}

1. Bangladesh Garment Manufacturers and Exporters Association. Impact of COVID-19 on Bangladesh RMH Industry. https://www.bgmea.com.bd/. Accessed July 20, 2020.

2. Parvin K, Mamun AM, Gibbs A, Jewkes R, Naved RT. The pathways between female garment workers' experience of violence and development of depressive symptoms. PLoS One. 2018;13(11):e0207485. doi:10.1371/journal.pone.0207485

3. Saxena S, Thornicroft G, Knapp M, Whiteford H. Resources for mental health: scarcity, inequity, and inefficiency. Lancet. 2007;370(9590):878-889. doi:10.1016/s0140-6736(07)61239-2

4. Islam A, Biswas T. Mental health and the health system in Bangladesh: situation analysis of a neglected domain. Am J Psychiatry Neurosci. 2015;3(4):57-62. doi:10.11648/j.ajpn.20150304.11

5. Pāla-Majumadāra P. Health status of the garment workers in Bangladesh. Dhaka, Bangladesh: Bangladesh Institute of Development Studies; 2003.

6. Akhter S, Rutherford S, Akhter KF, Bromwich D, Anwar I, Rahman A, Chu C. Work, gender roles, and health: neglected mental health issues among female workers in the ready-

\section{CONFLICTS OF INTEREST}

The authors have completed and submitted the ICMJE Form for Disclosure of Potential Conflicts of Interest and none was reported.

\section{FUNDING}

There was no source of funding for this research. made garment industry in Bangladesh. Int J Womens Health. 2017;9:571-579. doi:10.2147/ijwh.s137250

7. Portnoy J, Waller M, Elliott T. Telemedicine in the Era of COVID-19. J Allergy Clin Immunol Pract. 2020;8(5):14891491. doi:10.1016/j.jaip.2020.03.008

8. Centers for Disease Control and Prevention. CDC in Action. https://www.cdc.gov/coronavirus/2019-ncov/cases-updates/ cdc-in-action.html?CDC_AA_refVal=https $\% 3 \mathrm{~A} \% 2 \mathrm{~F} \% 2 \mathrm{Fwww}$. cdc.gov $\% 2$ Fcoronavirus $\% 2$ F 2019 -ncov $\% 2$ Fph p $\%$ 2Fpreparing-communities.html. Published July 8, 2020. Accessed July 20, 2020.

9. Ahmed T, Lucas $H$, Khan AS, Islam R, Bhuiya A, Iqbal M. eHealth and mHealth initiatives in Bangladesh: a scoping study. BMC Health Serv Res. 2014;14(1):1-9. doi:10.1186/1472-6963-14-260

10. Cosic K, Popovic S, Sarlija M, Kesedzic I. Impact of human disasters and Covid-19 pandemic on mental health: Potential of digital psychiatry. Psychiatr Danub. 2020;32(1):25-31. doi:10.24869/psyd.2020.25
YJ, VP, OMS and AS supported in the literature review and in critically reviewing the manuscript. All authors read and approved the final manuscript.

PROVENANCE AND PEER REVIEW

Not commissioned; internally peer reviewed. 